\title{
Expressões da ética e do distresse moral na prática do enfermeiro intensivista
}

\author{
Ethics and moral distress expressions in intensive care nursing practice \\ Expresiones de la ética y del distrés moral en la práctica del enfermero intensivista \\ Gláucia de Sousa Vilela1 ${ }^{1}$ io https://orcid.org/0000-0002-0727-5061 \\ Cecília Maria Lima Cardoso Ferraz' io https://orcid.org/0000-0001-6897-3798 \\ Danielle de Araújo Moreira² io nttps:/orcid.org/0000-0003-0846-0231 \\ Maria José Menezes Brito ${ }^{1}$ io https://orcid.org/0000-0001-9183-1982
}

Como citar: , Moreira DA, Brito MJ. Expressões da ética e do distresse moral na prática do enfermeiro intensivista. Acta Paul Enferm. 2021;34:eAPE01661.

DOI

http://dx.doi.org/10.37689/actaape/2021A001661

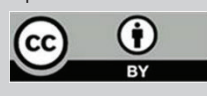

Descritores

Enfermeiras e enfermeiros; Ética; Cuidados críticos; Prática profissional; Estresse psicológico

Keywords

Nurses; Ethics; Critical care; Professional practice; Stress, psychological

Descriptores

Enfermeras y enfermeros; Ética; Cuidados críticos; Prática profissional; Estrés psicológico

Submetido
28 de Junho de 2020
Aceito
de Setembro de 2020

Autor correspondente

Gláucia de Sousa Vilela E-mail: glauciasvilela@yahoo.com.br

\section{Resumo}

Objetivo: Compreender as expressões da ética e do distresse moral na prática do enfermeiro intensivista.

Métodos: Pesquisa qualitativa, descritiva, interpretativa e analítica, desenvolvida com 12 enfermeiros lotados nos plantões diurnos do CTI de um hospital de ensino de Minas Gerais. Os dados foram coletados por meio de entrevistas, guiadas por roteiro semiestruturado e submetidos à análise de conteúdo.

Resultados: Emergiram duas categorias temáticas: Expressões da ética: Influências dos valores, virtudes, relacionamentos e organização do trabalho; e, Distresse moral no contexto das expressões éticas.

Conclusão: Na prática do enfermeiro intensivista, a ética está relacionada, principalmente, ao exercício da advocacia do paciente. No entanto, lacunas existentes nos relacionamentos com a equipe e na organização do trabalho, fomentam situações de conflitos geradoras de distresse moral.

\section{Abstract}

Objective: To understand ethics and moral distress expressions in intensive care nursing practice.

Methods: This is a qualitative, descriptive, interpretive and analytical research, developed with 12 nurses working on the day shifts in a ICU of a teaching hospital in Minas Gerais. Data were collected through interviews, guided by a semi-structured script and submitted to content analysis.

Results: Two thematic categories emerged: Ethics expressions: influences of values, virtues, relationships, and work organization; Moral distress in the context of ethics expressions.

Conclusion: In intensive care nursing practice, ethics is mainly related to the practice of patient advocacy. However, gaps in relationships with the team and in work organization encourage conflict situations that generate moral distress.

\section{Resumen}

Objetivo: Comprender las expresiones de la ética y del distrés moral en la práctica del enfermero intensivista.

Métodos: Investigación cualitativa, descriptiva, interpretativa y analítica, realizada con 12 enfermeros sobrecargados en las guardias diurnas de centros de terapia intensiva de un hospital universitario de Minas Gerais. Los datos fueron recopilados por medio de entrevista, con guion semiestructurado y sometidos al análisis de contenido.

Resultados: Surgieron dos categorías temáticas. Expresiones de la ética: influencias de los valores, virtudes, relaciones y organización del trabajo, y Distrés moral en el contexto de las expresiones éticas. 
Conclusión: En la práctica del enfermero intensivista, la ética está relacionada principalmente con el ejercicio de la defensa del paciente. Sin embargo, los vacíos existentes en las relaciones con el equipo y en la organización del trabajo fomentan situaciones de conflicto que generan distrés moral.

\section{Introdução}

A prática em saúde abrange dimensões éticas e é influenciada pela complexidade dos processos de trabalho. Nesta perspectiva, a expressão da ética perpassa por um exercício de reconstituição de si pelo sujeito, ${ }^{(1)}$ que acontece permanentemente ao longo da vida, tendo especial parcela de importância as experiências vivenciadas no labor.

Neste espaço de socialização, o indivíduo relaciona-se com seus pares e com o mundo, subjetiva a realidade apreendida e ressignifica seus conceitos, o que confere reconfiguração de si mesmo ${ }^{(2)}$ remodelando os modos de se perceber, de ser e agir no mundo. ${ }^{(3)}$

Assim, por meio das subjetivaçóes e da reflexão contínua sobre si mesmo o indivíduo constrói-se enquanto sujeito ético, moldando seu modo de ser e realizando o trabalho moral, mediado por valores, princípios e aspectos culturais. ${ }^{(3)}$ Neste sentido, a ética se expressa nas açóes e relações do indivíduo consigo mesmo e com o meio que o cerca, e, tomando indistintamente os termos ética e moral, considera-se a produtividade da experiência ético-moral "como contínua, infindável e produtiva em termos de subjetividade e identidade". ${ }^{(4,5)}$

Considerando que os espaços da prática do enfermeiro são caracterizados pelos encontros e relacionamentos deste profissional com seus pares e pacientes, estão presentes no cotidiano de trabalho experiências ético-morais, resultantes, por exemplo, de dissonâncias e conflitos, principalmente relacionados ao cuidado qualificado. ${ }^{(5)}$ Estudos evidenciam que, dentre os profissionais da saúde, os enfermeiros são aqueles que experienciam os problemas ético-morais com maior intensidade, ${ }^{(5,6)}$ podendo-se definir o problema moral por um fato ou situação que mobiliza a dúvida no indivíduo quanto ao modo adequado de ação, e que lhe exige posicionamento. (4)

Ao lançar um olhar sobre o Centro de Terapia Intensiva(CTI) percebe-se que este é um campo de trabalho do enfermeiro, marcado pela intensidade de sentimentos e relaçôes cotidianas que repercutem na prática do profissional, evidenciando aspectos éticos que envolvem o cuidado e as relaçóes interpessoais. ${ }^{(7)}$ Dentre os fatores que predispóem à vivência de conflitos ético-morais pelo enfermeiro no CTI, destacam-se o contato permanente com pacientes com necessidades de cuidados críticos, a presença da morte iminente, a vivência partilhada com pacientes e familiares da dor, da ansiedade, da angústia frente à doença grave e a utilização maciça de tecnologias duras para o cuidado. ${ }^{(7-9)}$

De tal modo, no cotidiano da terapia intensiva várias situaçóes se configuram como problemas morais, os quais exigem posicionamento por parte do enfermeiro. Salienta-se, entretanto, que a emergência de um problema ético-moral no trabalho requer do profissional sensibilidade para percebê-lo, bem como demanda a ação resolutiva ou deliberação, que se apresenta carregada de subjetividades, expressando concepçóes, culturas e valores próprios do enfermeiro. ${ }^{(4-6)}$

A sensibilidade moral é considerada um estado cognitivo que precede o julgamento moral, ${ }^{(10)}$ e a deliberação, uma conduta que se orienta por métodos, diálogo e raciocínio lógico, que visa resolver a situação problema. ${ }^{(4)}$ A deliberação do enfermeiro acontece em meio a um ambiente organizacional que interfere em sua concretude, ${ }^{(7)}$ podendo culminar em situaçôes em que deliberar, conforme seu julgamento moral, não seja possível, desencadeando-se a vivência do distresse moral no trabalho. ${ }^{(4)}$

A vivência do Distresse Moral (ou sofrimento moral, termos aqui entendidos como sinônimos) no cotidiano de trabalho do enfermeiro é uma experiência moral e pode gerar marcas deletérias ao profissional, manifestando-se por sentimentos de angústia, sensação de impotência, insatisfação, e, em casos reiterados e mais graves, pode ter como consequências a desmotivação, apatia, afastamentos do trabalho e abandono da profissão. ${ }^{(4,11)}$ No entanto, estudos ${ }^{(4,12)}$ consideram que a vivência do processo de distresse moral pode ser compreendida para além de uma vivência de sofrimento, consistindo 
em uma experiência ampla, fonte de resistência e enfrentamento no cotidiano de trabalho.

Vários fatores contribuem para que o distresse moral seja vivenciado no cotidiano e percebido pelo enfermeiro no contexto da terapia intensiva, podendo-se citar o desenvolvimento de sua sensibilidade moral, a autonomia do profissional, a organização e a estrutura física do espaço de trabalho, bem como as relaçôes de poder existentes. ${ }^{(5,7,10)}$ Estes fatores expressam a ética na prática do enfermeiro no que tange aos modos de organização do trabalho e suas relaçóes cotidianas, refletindo experiências morais ricas em significados e subjetividade.

Lançar os olhos sobre a ética e o distresse moral se justifica, considerando que as experiências morais são formas de expressão ética na prática do enfermeiro e que ainda podem ser atravessadas pelo distresse moral, produzindo efeitos deletérios sobre o profissional, ${ }^{(1)}$ bem como entendendo ser necessário compreender e refletir sobre as expressóes da ética e do distresse moral na prática do enfermeiro para que seu potencial produtivo seja abordado, ${ }^{(4,12)}$ importa debruçar sobre o estudo da expressão da ética e do distresse moral na prática do enfermeiro intensivista.

Em face do problema posto, o presente estudo buscou responder a seguinte questão norteadora: Como a ética e o distresse moral se expressam na prática do enfermeiro intensivista?

Para tanto, o presente estudo teve como objetivo compreender as expressóes da ética e do distresse moral na prática do enfermeiro intensivista.

\section{Métodos}

Tratou-se de uma pesquisa de abordagem qualitativa, descritiva, interpretativa e analítica, desenvolvida em um CTI de um Hospital Universitário localizado no estado de Minas Gerais. Os métodos e resultados desta pesquisa apresentam-se seguindo os preceitos definidos pelo Consolidated criteria for reporting qualitative research (COREQ).

A escolha do cenário da pesquisa foi intencional e considerou mudanças recentes em seu contexto organizacional, as quais promoveram novos arranjos no trabalho do enfermeiro. Como exemplo, destaca-se a gestão hospitalar desenvolvida pela EBSERH (Empresa Brasileira de Serviços Hospitalares), que instituiu o modelo de cuidados globais como modelo assistencial de enfermagem e o concurso público como forma de admissão no serviço.

A adoção deste modelo assistencial levou o enfermeiro a assumir direta e integralmente a assistência ao paciente, sendo auxiliado pelo técnico de enfermagem, desenvolvendo o cuidado "a beira leito". Considerando que estudos apontam que enfermeiros que atuam mais próximos aos pacientes tendem a vivenciar situações éticas com mais frequência ${ }^{(6)} \mathrm{e}$ ainda que as mudanças advindas dos novos arranjos organizacionais relacionados ao modelo assistencial de enfermagem impactaram na prática do enfermeiro, justifica-se a utilização deste cenário para este estudo.

Os participantes foram escolhidos intencionalmente, sendo incluídos os enfermeiros que atuavam no turno diurno do CTI e excluídos aqueles que atuavam no turno noturno, estivessem em gozo de férias regulamentares ou licenciados do serviço. A opção pelo turno diurno considerou que há singularidades entre a organização do trabalho diurno e noturno na instituição hospitalar, que potencialmente seriam significativas para a análise comum dos dados, podendo configurar-se por vieses na pesquisa.

Considerou-se inicialmente uma amostra de 20 enfermeiros, dos quais 2 estavam em gozo de férias regulamentares, se enquadrando, portanto, nos critérios de exclusão delimitados para o estudo. Dos demais enfermeiros, após serem convidados, 12 aceitaram participar e 6 recusaram-se na participação.

Os dados foram coletados em fevereiro de 2016, por meio de entrevistas guiadas por roteiro semiestruturado, as quais foram realizadas no próprio hospital, em local restrito, em horário previamente agendado, gravadas em aparelho eletrônico, com uma média de duração de trinta minutos. As entrevistas foram conduzidas por pesquisador previamente treinado, que se apresentou ao entrevistado, e elucidou os objetivos, aspectos éticos, recolhendo a anuência do entrevistado. A entrevista foi disponibilizada para o entrevistado, que pôde ouvi-la, para 
que, achando necessário, modificasse, excluísse ou acrescentasse alguma informação.

As entrevistas foram transcritas na íntegra e os dados foram submetidos à Análise Temática de Conteúdo, conforme os pólos cronológicos da pré-análise do material, da exploração do material e tratamento dos resultados e a inferência e interpretação. A fase de pré-análise fundamentou-se na organização e leitura flutuante do material, com a demarcação dos temas centrais. A exploração do material e o tratamento dos resultados permitiu torná-los significativos e válidos. A última etapa consistiu na inferência e interpretação dos dados. ${ }^{(13)}$

A pesquisa desenvolveu-se em conformidade aos princípios éticos expressos na Declaração de Helsinque e na Resolução do Conselho Nacional de Saúde Brasileiro número 466 de 2012, foi submetida à apreciação ética e aprovada pelo Comitê de ética em pesquisa da Universidade Federal de Minas Gerais sob o parecer $n^{\circ} 1.237 .831$. Todos os participantes assinaram Termo de Consentimento Livre e Esclarecido, expressando sua anuência em participar do estudo e a consciência sobre os desconfortos, riscos e benefícios da pesquisa. Com vistas a garantir o anonimato, os depoimentos foram codificados como Enf, seguido do número da respectiva entrevista.

\section{Resultados}

Da análise dos resultados, emergiram expressóes da ética e do distress moral, sendo delimitadas duas categorias analíticas.

\section{Expressões da ética: influência dos valores, virtudes, relacionamentos e organização do trabalho}

Os enfermeiros acreditam que a humanização pode evocar a responsabilidade e a empatia, sendo estes valores e virtudes fundamentais para o exercício do cuidado ético.

Primeiramente, humanização que está junto da empatia, que sáo os valores primordiais que eu acredito, a responsabilidade, empatia, humanizaçâo... eu acredito que também paciência (Enf 8).
Ser ético, ser humano, tentando proporcionar ao paciente e as pessoas um determinado conforto. Ser educado, saber até onde você pode ir, ir com delicadeza, com educação, com respeito ao momento que a pessoa está vivenciando. Eu acho que a ética abrange tudo. Tentar dar uma assistência de qualidade, dentro do conhecimento que eu tenho. Fazer para o outro aquilo que en gostaria talvez que fizessem por mim (Enf 2).

Para os participantes o fazer ético deve basear-se também nos códigos e normas da profissão, que estabelecem direitos e deveres profissionais frente ao cuidado.

Tentando ser o mais justo possível, muitas vezes náo pautado no que eu acho que seja justo, mas pautado no que a gente tem hoje palpável de legislação, de direitos, de deveres (Enf 6).

A ética se expressa no contexto do CTI suportada pelos valores morais e virtudes e, pelo código de ética profissional, e sofre interferências de fatores relacionais e organizacionais que, em muitas vezes, oferecem obstáculos para o exercício da ética pelo enfermeiro. Dentre estes obstáculos, os enfermeiros apontam que os desequilíbrios nas relaçóes de poder entre membros da equipe multidisciplinar inviabilizam a prática autônoma da enfermagem, fomentados principalmente pela maior valorização do saber médico.

O hospital deste estudo é, dos lugares que eu já trabalhei, o lugar mais médico centrado que eu já conheci na minha vida. Tudo aqui é muito médico centrado, tudo gira em torno de um conhecimento médico. E por mais que tenha o discurso de que o enfermeiro aqui tem autonomia, nossa autonomia é para fazer curativo e para gerir nossa escala, o resto, a nossa autonomia é muito pequena (Enf1).

Para os enfermeiros, a maior valoração do saber médico no contexto das práticas imputa-lhes uma prática muitas vezes inviabilizada e desvalorizada, submissa às determinações médicas. Inclusive, para Enf9, há valoração diferenciada no trabalho desenvolvido pelo enfermeiro assistencial e supervisor no contexto das relaçóes interprofissionais, atribuindo sentido ao desequilíbrio na relação médico-enfer- 
meiro existente neste espaço, em decorrência da mudança do modelo assistencial de enfermagem proposto pela EBSERH.

A questão médica aqui, que eu vim de outra instituição também, o "Hospital X" o tratamento médico e enfermeiro é diferente, apesar de serem dois hospitais escolas, o tratamento é completamente diferente. Eu acredito que lá, como nós éramos enfermeiros supervisores, a forma do médico ouvir o que a enfermagem tinha a dizer sobre a evolução daquele paciente era visto de uma forma, nós aqui continuamos sendo enfermeiros de nivel superior da mesma forma, só que a nossa fala sendo enfermeiro assistencial não tem o mesmo valor (Enf9).

Aqui o médico não avalia o paciente, não faz exame físico. Toda a avaliação do paciente é feita pelo enfermeiro, é o enfermeiro que passa as informaçóes. E mesmo com nossa preocupação eles não valorizam em nada o nosso conhecimento. A maior parte das vezes que o paciente sofre uma intervenção médica, ele só sofreu intervenção médica porque houve antes um reconhecimento da necessidade por um enfermeiro (Enf 1).

Os enfermeiros atribuem ainda à invisibilidade de sua prática a ausência de definição das atribuiçóes da equipe de enfermagem e a sensação de não pertencimento à equipe multidisciplinar.

Eu acho que o enfermeiro tem que ter um espaço como enfermeiro, profissional de uma equipe porque até então não tem! Quais são as funçóes do enfermeiro, qual a importância dele na equipe? Porque a equipe ainda náo aceita como um profissional (Enf 11).

Para os enfermeiros, a falta de comunicação constitui outra barreira importante à prática ética. Dentre as situaçóes apontadas pelos enfermeiros, cita-se a ausência de comunicação entre membros da equipe quer seja oral ou escrita e a organização.

A dificuldade eu acho que é essa, a questão da comunicação interna que uma das seis metas da segurança do paciente que tem no hospital, é comunicação efetiva, e o hospital não comunica efetivamente (Enf 3).

A gente tem muitos erros de residentes, muitos erros médicos. Prescriçóes erradas, por exemplo, são problemas que a gente tem o tempo todo, prescriçóes verbais que muitas vezes não são registradas, o que acaba caindo sobre a equipe de enfermagem (Enf6).

Os participantes apontam para a falta de comunicação da equipe com os pacientes, destacando as situações de omissão de iatrogenias, a discussão sobre a limitação terapêutica e a despersonificação do paciente que acontece durante a "corrida de leito". Ressalta-se que o termo "corrida de leito" refere-se à visita do profissional de saúde ao paciente que se encontra restrito ao leito hospitalar, realizando a avaliação e o planejamento do cuidado.

O paciente vai para o bloco cirúrgico entubado e sedado para uma cirurgia de emergência. Eu acho que é ser ético com o paciente perguntar se a familia desse paciente está ciente que ele está indo para o bloco. Porque já aconteceu de mudar o horário da cirurgia cardiaca de um paciente que seria à tarde, mudaram o horário para de manhã e ninguém prestou atenção nisso. Na hora que a familia chegou para visitar o paciente e aí, cadê o paciente? Já está lá no bloco. A irmã dele questionou: Gente, se o meu irmáo morrer? Não tive nem oportunidade de me despedir e nem falar nada (Enf2).

A iatrogenia ou a limitaçâo do cuidado, como que isso é estabelecido em relaçâo de trabalho. Como isso deve ser tratado com a familia e com a sociedade? Deve constar no prontuário, mas na maioria das vezes vai ser abafado no ambiente intra-hospitalar. São questóes éticas que eu considero importantes serem discutidas (Enf8).

O que mata, o que nos incomoda muito é a relação deles (médicos) com os pacientes. Durante a corrida de leito tem 12, 15 pessoas fazendo corrida de leito com o paciente consciente, falando do exame, e ai às vezes eles estão falando do exame do paciente do 
305 na frente do 308. O paciente arregala o olho! Ai você tem que falar para ele: não fulano, calma, não é do senhor que ele está falando (Enf1).

\section{Distresse moral na prática do enfermeiro intensivista}

Os resultados apontam que há momentos em que o enfermeiro se depara com situaçóes com as quais não concorda e não tem condiçôes para modificá-las, experienciando, de tal modo, o distresse moral.

Por exemplo, um paciente que tem uma prescrição de laxante. Informei que o paciente evacuou a noite, quatro vezes. E vem lá na prescrição de novo um laxante! Então para que você está ali? Ninguém está nem aí para essa informação! Você náo tem nem uma oportunidade de falar isso ali na passagem de plantão! Quem está lá na beira do leito é o enfermeiro! O médico não te escuta, e ai depois tenho que ficar correndo atrás dele: "olha aqui médico! Circula aqui esse laxante porque ele já não está precisando mais!". (Enf 12).

Você não tem uma coordenadora, nada. Ninguém que te escute. A pessoa te escuta e fala assim "ah tá, nós vamos resolver...", mas parece que ela está falando o que você quer ouvir, mas na verdade não vai ter resultado. É tapar um sol com a peneira! Mas não resolve nada, é como se tivessem dois ouvidos, um pra entrar e outro pra sair. Às vezes você observa alguma coisa em relação a escala, ao serviço e consegue refletir, mas e daí?! O quê que você vai fazer com aquilo? Ninguém te escuta, a equipe multidisciplinar não te escuta! Você tenta fazer um trabalho e ninguém quer te ouvir, então, tanto faz né?! (Enf 12).

A evidência do distresse moral manifestou-se nas falas dos enfermeiros quando da impossibilidade de desempenharem a advocacia do paciente, quer seja em face da ausência do cuidado necessário, como afirma Enf 11, ou em situaçôes de obstinação terapêutica, conforme exemplifica Enf 8.

Quando peguei plantão a paciente já estava com queixa de dor intensa, sem acesso venoso. A gen- te tentou sem sucesso um acesso para a medicação! Comunicamos da necessidade de um acesso central nela, mas os médicos foram para a corrida de leitos e não fizeram o procedimento. Discuti com um colega porque eles acham que precisam discutir os casos todos antes de resolver os problemas dos pacientes. Eu lembro de trocar ela com dor, aspirar, dar banho e ela gemia! Eu fui ficando muito angustiada, eu saí daqui muito angustiada! Foi uma situação de bastante conflito, angústia, frustração! Sai frustrada porque não fiz para a paciente o que podia! Pedi medicação intramuscular, mas ele falou que ela poderia esperar o procedimento. Então eu virei nada, porque eu falava, a paciente piorava e nada era feito (Enf 11).

O paciente foi diagnosticado em cuidado limitado. Então nós não vamos tomar providências muito exageradas quanto a esse paciente, só manter a dignidade dele. Ele apresentou hipotensão e o médico pediu pra correr volume e providenciar material para o acesso central. Questionei se trocaria o acesso mesmo com diagnóstico limitado. O médico disse que sim. É uma medida que eu náo concordo! Se o paciente está limitado, e já tem um acesso central com foco infeccioso e se não vai investir mesmo, por que trocar o acesso central? É um gasto a mais, um sofrimento a mais, uma exposição a mais a invasão! Ai eu fiz, porque eu estou subordinado a prescrição médica. A decisão da conduta é dele! Eu argumentei, ele viu que eu senti, eu transpareci para ele que eu náo concordava, e mesmo assim ele quis manter a conduta (Enf 8).

\section{Discussão}

Os resultados deste estudo demonstram que as expressóes da ética se relacionam à prática do enfermeiro, considerada uma ação moral que visa alcançar o cuidado ao paciente pelo atendimento de suas necessidades. $^{(14)}$

Os dados apontam que os enfermeiros são sensíveis moralmente às questóes éticas cotidianas, relacionam a existência de problemas morais à situaçóes inerentes ao contexto das relaçóes em equipe, 
ao relacionamento com a própria instituição, com os pacientes e familiares, e também ao exercício da advocacia do paciente.

A sensibilidade moral pode ser tratada como um atributo ou habilidade individual para detectar e reconhecer em uma situação seu aspecto ético-moral. Há evidências que a percepção dos enfermeiros sobre os aspectos ético-morais envolvidos no cuidado, bem como o modo como estes enfermeiros lidam com as questóes éticas no trabalho tem influência multifatorial, expressando-se diferentemente em cada nação. ${ }^{(7,10)}$ Tal evidência apoia-se na fundamentação de que a sensibilidade moral relaciona-se com a cultura, com a formação profissional, com a religião, com as experiências na ação reflexiva sobre si, sobre o outro, sobre normas e instituiçôes e, com as subjetivações possíveis ao longo da vida. ${ }^{(4,7,10,14)}$

O desenvolvimento da sensibilidade moral é contínuo, progressivo ${ }^{(14)}$ e fundamental para a identificação das questóes éticas que se apresentam no contexto do trabalho do enfermeiro em terapia intensiva, oferecendo ferramentas para a definição de problemas morais, bem como para subsidiar as deliberaçôes em face do problema posto. ${ }^{(7)}$ De tal modo, a sensibilidade moral configura-se como atributo essencial ao trabalho do enfermeiro nos centros de terapia intensiva, visto a necessidade de o profissional ser permanentemente reflexivo sobre a melhor conduta a ser tomada para atingir o cuidado. No âmbito da terapia intensiva prescinde ao enfermeiro agir clínica, crítica e eticamente em um ambiente emocionalmente carregado pela gravidade dos casos clínicos, pela alta tecnologia exigida para o cuidado e pela complexidade da assistência prestada. ${ }^{(5,15)}$

Estudo $^{(5)}$ identificou que a sensibilidade moral de enfermeiros que atuam em unidades de terapia intensiva pode ser estratificada por seus componentes em três categorias: consciência moral, percepçáo moral espontânea e motivação benevolente. A consciência moral compreende a ciência pelo enfermeiro dos princípios éticos expressos no código de ética profissional, que se torna o instrumento norteador do diagnóstico de problemas éticos no trabalho e guia da ação ética sobre estes problemas. A percepção moral espontânea reflete a capacidade de reconhecimento pelo enfermeiro das questóes éticas que envolvem dada situação, como a definiçãao do problema ético, os sentimentos dos envolvidos nesta situação e, os impactos das ações sobre os envolvidos. Da motivação benevolente participa a vontade do enfermeiro em fazer aquilo que acredita ser correto visando o bem do paciente, sensibilizando-se a partir de valores pessoais. ${ }^{(16)}$

Estes achados corroboram os resultados do presente estudo, no qual também foi possível perceber que os fundamentos da ética benevolente se aplicam à sensibilidade moral da prática do enfermeiro. Valores e virtudes pessoais que compóem traços da sua identidade foram apontados como norteadores da prática ética, podendo-se citar o respeito, a empatia, a vontade de fazer ao outro como gostaria que fosse feito a si mesmo, e são considerados como um guia à prática com excelência. ${ }^{(17)}$ Os valores aplicados na ação moral caracterizam o cuidado ético e ainda influenciam sobremaneira as deliberaçóes. ${ }^{(6,8,18)}$

A sensibilidade para problematizar as situaçóes que envolvem aspectos éticos aliando valores e virtudes pessoais, os saberes profissionais, estrutura organizacional, relacionamentos em equipe, protocolos, normas e os códigos de ética torna-se elemento fundamental para a deliberação moral. ${ }^{(15)}$ Tal articulação entre consciência moral, percepção moral espontânea e motivação benevolente permite ao enfermeiro deliberar, traçando soluçóes prudentes e responsáveis para determinado problema moral, ${ }^{(15)} \mathrm{e}$, além disso, transcender os problemas éticos de modo que eles não constituam barreiras ao exercício do cuidado. ${ }^{(5)}$ Estudo sobre a sensibilidade moral na prática de enfermeiros de unidade de internaçáo evidenciou a relevância da formação profissional pautada no desenvolvimento de competências e habilidades que permitam aos enfermeiros mobilizar e articular saberes e valores para as tomadas de decisóes em seu cotidiano de trabalho. ${ }^{(19)} \mathrm{A}$ importância da formação ética do enfermeiro intensivista com vistas a desenvolver competências, valores e sensibilidade moral também foi evidenciada na literatura. ${ }^{(5)}$

O compromisso ético do enfermeiro em garantir o cuidado e a defesa do paciente expressou-se em sua prática. Estudos apontam que, relacionando-se ao cuidado e à defesa do paciente em suas singularidades, o papel principal do trabalho do enfermeiro 
tem em sua essência, relação direta com a moral e a atividade fundamental da enfermagem pode ser vista na defesa do paciente. ${ }^{(20,21)}$

O exercício da advocacia do paciente expressa a ética neste cenário, e se configura como um objetivo do trabalho do enfermeiro frente ao cuidado. ${ }^{(22)} \mathrm{A}$ advocacia se constitui por um conjunto de práticas que envolvem esforços do profissional para garantir os interesses dos pacientes, no âmbito dos seus direitos, no acesso à informação para tomada de decisóes sobre sua saúde, no alcance de bens e serviços necessários ao seu cuidado. ${ }^{(15,21,23)} \mathrm{A}$ defesa do paciente com dor, ou em cuidados paliativos, como apontado nos resultados deste estudo, foi relacionada como campo de práticas de advocacia pelo enfermeiro também em outro estudo. ${ }^{(20)}$

Esta ação potencializa-se por meio do modelo de cuidados de enfermagem adotado, que aproxima o enfermeiro da assistência e do reconhecimento das necessidades dos pacientes sob seus cuidados, contribuindo ainda com o desenvolvimento da sensibilidade moral destes enfermeiros.

No entanto, os dados apontam que não basta somente a vontade do enfermeiro para concretizar o trabalho da forma que julga mais adequada. Fatores inerentes ao relacionamento interpessoal e à organização do trabalho atravessam a prática, muitas vezes oferecendo barreiras para as deliberaçóes conforme seu julgamento moral, culminando na vivência de distresse moral pelo enfermeiro. ${ }^{(7)}$

O distresse moral acontece em meio a "microespaços de poder em que a prática profissional é desenvolvida", ${ }^{(21)}$ ambiente em que se dão as relaçóes e onde os sujeitos envolvidos têm a possibilidade de deliberar sobre problemas morais cotidianos. Nestes microespaços oportunizam-se situaçóes conflituosas que se relacionam à dinâmica do trabalho no contexto organizacional, capazes de fragilizar as práticas éticas no contexto do trabalho. ${ }^{(7)}$

Tendo em vista os depoimentos, emergiram situaçóes conflituosas que fragilizam as práticas éticas e ampliam os desequilíbrios nas relaçóes de poder entre os membros da equipe (principalmente entre médicos e enfermeiros), a indefinição das atribuiçôes da equipe de enfermagem e, a ausência de comunicação efetiva no contexto do trabalho. Isoladas ou em conjunto, percebeu-se que estas barreiras inviabilizam o exercício da advocacia do paciente pelo enfermeiro, sendo esta uma situação geradora de distresse moral. ${ }^{(21)}$

No campo dos desequilíbrios das relações de poder, os enfermeiros referem que o saber médico norteia o cuidado no CTI deste estudo, razão pela qual se percebem submissos ao trabalho médico. Referem ainda ter sua autonomia e seu conhecimento científico cerceado e seu trabalho reduzido ao cumprimento de prescriçóes, o que é apontado como situação não ética pelos enfermeiros e geradora de distresse moral. ${ }^{(7,9,10)}$ Constrói-se na disputa de poder um campo de conflitos éticos, ${ }^{(7,24)}$ posto que nem todos os saberes dos membros da equipe são valorizados nas deliberaçóes dos problemas ético-morais emergentes.

No entanto, vale ressaltar, conforme apontado em estudo sobre deliberaçóes morais do enfermeiro frente a internação por ordem judicial ${ }^{(15)}$, que há diferenças na natureza do trabalho médico e de enfermagem. A prática médica direciona-se ao que deve ser feito para a cura da doença, utilizando-se de todas as possibilidades terapêuticas. Já a prática da enfermagem, direcionada ao cuidado e ao atendimento das necessidades do paciente, volta-se ao relacionamento, à proximidade e à advocacia, e muitas das vezes, oferece subsídios para a discussão de até onde deve ir o investimento terapêutico, sem que haja obstinação. ${ }^{(15)}$

Os dados revelados nesta pesquisa corroboram com o que foi elucidado em outro estudo ${ }^{(15)}$ sobre a natureza do trabalho dos enfermeiros. Foi possível perceber que a insensibilidade para o reconhecimento da natureza das profissóes limita a autonomia delas e o impedimento de os enfermeiros se manifestarem por meio do diálogo com a equipe, gera distresse moral em face da impossibilidade de agir conforme seu julgamento moral. A disputa de poder é geradora de conflitos éticos e pode ser mobilizada pela falta de coesão entre a equipe e pelo desconhecimento do papel do outro no contexto do trabalho. ${ }^{(24)}$

Ressalta-se que exercer a advocacia pressupóe assumir uma posição que pode ser geradora de conflitos entre os membros da equipe, visto que potencialmente desvela diferentes opinióes acerca do 
melhor cuidado ao paciente, desequilibrando relaçóes de poder, "especialmente entre a medicina e a enfermagem". (23)

Os enfermeiros deste estudo referem que desempenham atividades assistenciais diretas a beira leito do paciente, conforme estabelecido pela reorganização do modelo assistencial de enfermagem proposto pela EBSERH e percebem que esta posição qualifica o cuidado e potencializa o exercício da advocacia do paciente. No entanto, também percebem que os demais membros da equipe não reconhecem as atividades assistenciais a beira leito que desenvolvem como diferenciais para o cuidado qualificado, relacionando-a à atividades menores, que em outros tempos eram realizadas somente por técnicos de enfermagem.

Neste caso, a divisão do trabalho gerencial e assistencial do enfermeiro ganha aspectos sociais e políticos, visto que alcança a dimensão da autonomia profissional. ${ }^{(25)}$ Aos enfermeiros que exercem atividades majoritariamente assistenciais não é acessível a participação nas discussóes em equipe, gerando neles sentimentos de invisibilidade e desvalorização. Tal invisibilidade torna sua prática desacreditada perante a sociedade e seus pares, influenciando a qualidade do cuidado, a ética e a motivação dos enfermeiros. $^{(9)}$

Aliado a este fato, há a manifestação pelos enfermeiros entrevistados da percepção da ausência do papel da coordenação na defesa dos enfermeiros e de sua autonomia. De tal modo, percebem-se deslocados da prática, limitados para interferirem nos processos deliberativos que envolvem o cuidado, havendo indícios de que suas deliberaçóes morais sobre os problemas definidos no cotidiano estagnem-se ou não se concretizem.

A autonomia do enfermeiro deve ser garantida na prática, tendo em vista que a enfermagem é uma profissáo legitimada pelas leis de exercício profissional nas quais se pode citar a Lei 74.98/86 e o Decreto 94.406/87, e pela construção histórica e social da profissão, pautada em formação científica sólida, robusta, crítica e reflexiva. ${ }^{(25)}$

A percepção de invisibilidade do trabalho pelo enfermeiro manifesta-se em outro obstáculo à prática ética, apontado nos resultados, que se refere à falta de comunicaçáo efetiva entre os membros da equipe multiprofissional, bem como entre a equipe e os pacientes e familiares.

Destacam-se situaçôes nas quais informaçôes essenciais aos pacientes não são comunicadas, principalmente quando do planejamento do cuidado ou da limitação da assistência terapêutica pela gravidade e irreversibilidade do quadro clínico. Especialmente essas situaçóes são geradoras de distresse moral ao enfermeiro, pois, reconhecendo-as como problema moral, não conseguem intervir nelas como julgam correto devido à barreira comunicativa existente.

No campo das comunicaçóes, os resultados evidenciam a presença de prescriçóes médicas que acontecem verbalmente e a omissão das iatrogenias do cuidado, julgadas como práticas não éticas pelos enfermeiros. A falta de comunicação, dentre outros fatores, é apontada em estudo, ${ }^{(21)}$ como situação cotidiana no trabalho do enfermeiro que reflete na vivência de sentimentos deletérios no trabalho, tais como a impotência em atender às necessidades dos pacientes, culminando na sensação de angústia e insatisfação.

Fica claro que o conjunto das barreiras organizacionais, de relacionamento e de comunicação que se apresentam no trabalho geram dificuldades para o enfermeiro deliberar em conformidade com seu julgamento moral em sua prática, gerando distresse moral neste profissional, principalmente quando da impossibilidade de exercer a advocacia do paciente.

Importa destacar a relevância da organização institucional no que tange aos resultados deste estudo. É papel da organização delinear o curso do trabalho das equipes profissionais, oferecendo suporte para a redução dos agentes estressores, fomento da autonomia e do diálogo, garantia de estrutura e insumos suficientes para a prática, mobilizando a coesão da equipe em prol do cuidado qualificado. ${ }^{(26)}$ Pelos resultados, percebeu-se que há lacunas na organização do trabalho do enfermeiro que fomenta a emergência de problemas morais advindos das tensóes concorrentes entre a lógica da prática do enfermeiro e a lógica institucional que ainda supervaloriza o saber médico na condução terapêutica dos casos clínicos.

Os achados deste estudo corroboram os dados apontados por outro estudo que menciona que dentre as principais barreiras organizacionais para o 
exercício da advocacia pelo enfermeiro destacam-se a relação com a equipe médica, falta de tempo pela elevada carga de trabalho, comunicação inefetiva com o paciente ou com a equipe multiprofissional, impotência e falta de autonomia do enfermeiro. ${ }^{(23)}$

Os sentimentos manifestos pelos enfermeiros que se relacionam à vivência do distresse moral no trabalho, tais como incômodo, frustração, angústia, invisibilidade, expressam a insatisfação do profissional frente ao trabalho e, portanto, remetem à importância de se buscar alternativas para o enfrentamento do distresse moral por meio da construção de espaços de práticas éticas mais expressivas neste cenário.

Neste sentido, os resultados permitiram reafirmar que o fortalecimento de discussóes sobre prática ética em momentos de educação em serviço, bem como a sua ampliação durante a graduação é uma estratégia positiva para o reconhecimento de situaçóes éticas no cotidiano, desenvolvimento de valores morais, qualificação das condutas profissionais e enfrentamento ao distresse moral, refletindo positivamente sobre o cuidado prestado pelo enfermeiro em centros de terapia intensiva. ${ }^{(22)}$

Portanto, sugere-se a adoção de momentos de discussáo entre os profissionais, com o objetivo de estreitar vínculos, fomentar o diálogo entre a equipe, a gestão e os usuários do serviço. Tais atitudes podem repercutir positivamente sobre o cuidado prestado, bem como reduzir o distresse moral entre os profissionais, culminando em um espaço de maior expressão ética.

Ainda, é preciso desenvolver estratégias para aproximar os valores profissionais aos valores organizacionais, de modo que a vivência do cuidado pelo enfermeiro aconteça em um espaço mais ético, que considere a excelência da prática e subjetividades que envolvem o ato de cuidar. ${ }^{(17)}$

Os resultados deste estudo possibilitaram explorar um fenômeno específico relacionado a enfermeiros de um centro de terapia intensiva de um único hospital que adota o modelo global de cuidados como modelo assistencial de enfermagem. Deste modo, mais estudos devem ser conduzidos para que estas questóes também possam ser exploradas em outros espaços de trabalho do enfermeiro. Salientase, no entanto, que, considerando ser a ética inerente à prática do enfermeiro, os resultados desta investigação podem aplicar-se, subsidiando discussôes acerca da construção de relações éticas que vislumbram o cuidado ao paciente considerado como o objeto do fazer em saúde.

\section{Conclusão}

O estudo permitiu compreender as expressóes da ética e do distresse moral na prática do enfermeiro intensivista, relacionando-se principalmente ao cuidado e às relaçóes que se estabelecem no contexto do trabalho. A advocacia ao paciente se mostrou como a forma mais expressiva da ética no trabalho do enfermeiro, denotando seu compromisso ético perante o cuidado de excelência e à defesa das necessidades do paciente. Em contraponto, notou-se que fatores intervenientes como a falta de clareza quanto à natureza do trabalho e às atribuiçóes de cada membro da equipe multiprofissional, os desequilíbrios nas relaçôes de poder, bem como a falta de comunicação entre a equipe multiprofissional, desencadearam um ambiente propício a emergência de problemas morais, cujos desfechos apontaram para lacunas na prática ética. Importa considerar que, principalmente em face da impossibilidade de exercer a advocacia do paciente, foram reveladas situaçóes de vivência de distresse moral pelos enfermeiros, inclusive com marcas residuais desta vivência sobre eles próprios.

\section{Agradecimentos}

Ao Conselho Nacional de Ciência e Tecnologia (CNPq); à Coordenação de Aperfeiçoamento de Pessoal de Nível Superior (CAPES); à Fundação de Amparo a Pesquisa do Estado de Minas Gerais (FAPEMIG), ao Núcleo de Pesquisa de Administração em Enfermagem (NUPAE).

\section{Colaborações}

Vilela GS, Ferraz CMLC, Moreira DA e Brito MJM contribuiu com a concepção e projeto, análise e interpretação dos dados, redação do artigo, da revisão 
crítica relevante do conteúdo intelectual e aprovaçáo final da versão a ser publicada.

\section{Referências}

1. Foucault M. A ética do cuidado de si como prática da liberdade. In: Ditos \& Escritos V - Ética, Sexualidade, Política. Rio de Janeiro: Forense Universitária; 2004. p. 264-87.

2. Berger PL., Luckmann T. A Construção social da realidade. Tratado de sociologia do conhecimento. Petrópolis: Vozes; 1973.

3. Pivoto FL, Lunardi Filho WD, Lunardi VL, Silva PA. Organization of work and the production of subjectivity of the nurse related to the nursing process. Esc Anna Nery. 2017;21(1):e20170014.

4. Ramos FR, Barlem EL, Brito MJ, Vargas MA, Schneider DG, Brehmer LC. Conceptual framework for the study of moral distress in nurses. Texto Contexto Enferm. 2016;25(2):e4460015.

5. Schallenberger CD, Tomaschewski-Barlem JG, Barlem EL, Rocha LP, Dalmolin GL, Pereira LA. Moral sensitivity components identified among nurses from Intensive Care Units. Rev Bras Enferm. 2019;72 Suppl 1:2-8.

6. Nora CR, Deodato S, Vieira MM, Zoboli EL. Elements and strategies for ethical decision-making in nursing. Texto Contexto Enferm. 2016;25(2):e4500014.

7. Lluch-Canut $T$, Sequeira C, Falcó-Pegueroles A, Pinho JA, Rodrigues-Ferreira A, Olmos JG, Roldan-Merino J. Ethical conflicts and their characteristics among critical care nurses. Nurs Ethics. 2020;27(2):537-53

8. Nascimento ER, Gulini JE, Minuzzi AP, Rasia MA, Danczuk RF, Souza $\mathrm{BC}$. [Intensive care unit nursing relationships in the view of Paterson and Zderad]. Rev Enferm UERJ. 2016; 24(2):e5817. Portuguese.

9. Caram CS, Peter E, Brito MJ. Invisibility of the self: reaching for the telos of nursing within a context of moral distress. Nurs Inq. 2019;26(1):e12269.

10. O'Connell CB. Gender and the experience of moral distress in critical care nurses. Nurs Ethics. 2015;22(1):32-42.

11. Ramos FR, Barth PO, Schineider AM, Cabral AS, Reinaldo JS. [Effects of moral distress on nurses: integrative literature review]. Cogitare Enferm. 2016;21(2):1-13. Portuguese.

12. Ramos FR, Barth PO, Brito MJ, Caram CS, Silveira LR, Brehmer $\mathrm{LC}$, et al. Aspectos sociodemográficos e laborais associados ao distresse moral em enfermeiros brasileiros. Acta Paul Enferm. 2019;32(4):406-15.

13. Bardin L. [Content analysis]. Lisboa: Edições 70; 2016. Portuguese.

14. Amiri $E$, Ebrahimi $H$, Vahidi $M$, Asghari Jafarabadi $M$, Namdar Areshtanab H. Relationship between nurses' moral sensitivity and the quality of care. Nurs Ethics. 2019;26(4):1265-73.

15. Luz KR, Vargas MA, Barlem EL, Schineider DG, Neves FB. [Moral deliberation of nurses facing hospitalization by court order]. Rev Enferm UFSM. 2019;9 e27:1-20. Portuguese.

16. Boonyamanee B, Suttharangsee W, Chaowalit A, Parker ME. Exploring moral sensitivity among Thai psychiatric nurses. Songklanagarind J Nurs. 2014;34(1):35-43.

17. Caram CS, Brito MJ, Peter E. [Hospital accreditation: excellence as a source of moral distress for nurses]. Enferm Foc0. 2019;1(1):31-5. Portuguese.

18. Barlow NA, Hargreaves J, Gillibrand WP. Nurses' contributions to the resolution of ethical dilemmas in practice. Nurs Ethics. 2018;25(2):230-42.

19. Moreira DA, Ferraz CM, Costa IP, Amaral JM, Lima TT, Brito MJ. Estratégias de comunicação efetiva no gerenciamento de comportamentos destrutivos e promoção da segurança do paciente. Rev Gaúcha Enferm. 2019;40 (Spe):e20190080.

20. Tomaschewski-Barlem JG, Lunardi VL, Barlem EL, Silveira RS, Ramos AM, Santos JM. Ações dos enfermeiros no exercício da advocacia do paciente: revisão integrativa. Texto Contexto Enferm. 2018;27(2):e0730014.

21. Barlem EL, Ramos FR. Constructing a theoretical model of moral distress. Nurs Ethics. 2015;22(5):608-15.

22. Monroe HA. Nurses' professional values: influences of experience and ethics education. J Clin Nurs. 2019;28(9-10):2009-19.

23. Tomaschewski-Barlem JG, Lunardi VL, Barlem EL, Silveira RS, Ramos AM, Piexak DR. Advocacia do paciente na enfermagem: barreiras, facilitadores e possíveis implicações. Texto Contexto Enferm. 2017;26(3):e0100014.

24. Montenegro LC, Rennó HM, Caram CS, Brito MJ. Problemas éticos na prática de profissionais de saúde em um hospital escola. Av Enferm. 2016;34(3):226-35

25. Bellaguarda ML, Padilha MI, Pereira Neto AF, Pires D, Peres MAA. [Reflection on the legitimacy of the autonomy at nursing in the field of the health professions in the light of Eliot Freidson's ideas]. Esc Anna Nery. 2013; 17 (2):369-74. Portuguese.

26. Ferreira GB, Aragão AE, Oliveira PS. [Burnout syndrome in hospital/ intensive nursing care: what do the studies say?]. Sanare. 2017;16(1):100-8. Portuguese. 